\title{
Medellín, el reto de la innovación
}

\author{
Nidia Albeny Rodríguez Tamayo*
}

$\mathrm{E}$ pasado $1^{\circ}$ de marzo, Medellín fue destacada por el Urban Land Institute como la ciudad más innovadora del mundo, gracias a sus avances y a su potencial inclusión, a los esfuerzos por mejorar la calidad de la educación y al impulso de la investigación y las soluciones de movilidad.

Esta mención representa para la ciudad, en especial para los académicos e investigadores que la habitamos, un gran reto, que nos conmina a abordar asuntos como:

- La necesidad de entender la actividad investigativa como un ejercicio de creación y búsqueda de maneras novedosas, eficientes y eficaces de intervenir en el entorno; esto abarca desde la invención de nuevos mecanismos y sistemas hasta la resignificación y adaptación del conocimiento a nuestra realidad social, económica, cultural, política y ambiental.

- La innovación como atributo coadyuvante de los esfuerzos de inclusión social, que permita proyectar una ciudad menos desigual, más digna para los miles de personas que la habitamos.

- La innovación como una cualidad fundamental en la práctica cotidiana de nuestros investigadores, que les obligue a interrogarse, a sacudir continuamente las bases de su conocimiento.

- El fortalecimiento de la interacción de la Universidad, la empresa y el Estado, entendiendo que este es el ambiente propicio para viabilizar las iniciativas en aras de la construcción de riqueza social.

- La necesidad de potenciar las cualidades creativas y recursivas propias de la actividad investigativa de los países en desarrollo en torno a la innovación.

- La importancia de sintonizarnos con la vocación productiva de la ciudad y la región consultando y aportando a las políticas públicas que apuntan a su desarrollo.

- La posibilidad de mejorar, a través del ejercicio investigativo, la calidad de la educación superior, y, por ende, de los nuevos profesionales que constituyen el capital humano para el proyecto de ciudad innovadora.

- La oportunidad de aportar a la preparación del aparato productivo y de servicios, para acoger las inversiones que a mediano y largo plazo se radicarán en la ciudad y la región.

- La interdisciplinariedad y también la transdisciplinariedad, como elementos constitutivos de la innovación, que invitan a articularnos en redes y grupos de apoyo que proyecten nuestra investigación y potencien sus atributos.

- La sostenibilidad ambiental, económica y social de los proyectos investigativos, como condición de las iniciativas de innovación.

En especial, vale la pena destacar uno de los aspectos más importantes a los que nos reta esta calificación de ciudad innovadora, y es que nos exhorta a crear sinergias 
con el entorno político y social. Por ello la innovación debe beber de los lineamientos estratégicos que desde la planeación pública se construyen para la ciudad, la región y el país.

El titulo adquirido por Medellín no es un mero ejercicio de lobby con efectos publicitarios para la ciudad: es el producto de una serie de esfuerzos institucionales que vienen reconfigurando la vocación productiva de la ciudad, a partir de la crisis industrial de la última década del siglo pasado. Muestra de estos esfuerzos se puede observar en los siguientes documentos de política pública, los cuales debemos entronizar en nuestro quehacer investigativo cotidiano:

El Plan de Ciencia, Tecnología e Innovación de Medellín, que se constituye en un documento novedoso de la planeación política en nuestro país, visualiza una ciudad que al 2021 goce de altos niveles de vinculación entre la academia y los sectores productivos, políticos y sociales como condición propiciadora de un desarrollo integral de la misma. Este plan define tres cadenas productivas prioritarias a partir de las potencialidades de la ciudad y la región: energía, TIC y salud, las cuales deben enriquecerse con un alto valor agregado, dado por el conocimiento, de tal manera que otorgue la competitividad necesaria para enfrentarse a un mercado globalizado.

La alianza ama (Alianza Medellín y Antioquia) da a la categorización de Medellín como ciudad innovadora un alcance regional, en la medida en que este acuerdo estratégico entiende que el desarrollo de la capital está indisolublemente ligado al del territorio en el cual se enmarca. Por ello plantea que los esfuerzos en educación, fortalecimiento del aparato productivo, acercamiento de la empresa, la academia y el Estado, deben ser abordados de manera conjunta por las administraciones de las entidades territoriales que la conforman.

Los planes de desarrollo "Medellín un hogar para la Vida 2012-2015" y "Antioquia la más Educada" conciben el conocimiento como una herramienta fundamental para el avance y la competitividad de la ciudad y la región, y así lo plasman en sus líneas estratégicas, componentes y programas.

En este marco jurídico, político e institucional, la Universidad está llamada a incidir en la ciudad y la región como abanderada, propiciadora del conocimiento que el desarrollo demanda. Nuestros docentes y los profesionales en formación deben ser capaces de generar propuestas de avance que respondan a esta dinámica territorial, con un enfoque crítico y social.

La Universidad Cooperativa de Colombia, en particular, debe potenciar fortalezas, como su origen solidario, la incidencia en las comunidades que la rodean, su presencia nacional y regional, al igual que la alta calidad de sus profesionales, creando un sello de producción de conocimiento propio que le permita obtener relevancia en esta nueva realidad.

En la región, las áreas de salud e ingeniería son aspectos clave de incidencia, que unidos al componente solidario, permitirían a la Universidad proponer soluciones novedosas a las problemáticas sociales y de desarrollo, como la violencia, la marginación y la exclusión, máxime si se considera un posible escenario de posconflicto, en el que nuestro territorio está llamado a liderar acciones de reconciliación y reconstrucción social.

Nuestro llamado entonces es, desde la investigación, a proyectar nuestra visión hacia los desafíos que la realidad descrita nos presenta, y a plasmar en el quehacer académico una visión de ciudad y región más incluyente, justa y equitativa para todos.

${ }^{*}$ Coordinadora del Centro de Investigaciones

Universidad Cooperativa de Colombia, sede Medellín 